Article

\title{
Assessment of the Antimicrobial, Antioxidant, and Antiproliferative Potential of Sideritis raeseri subps. raeseri Essential Oil
}

\author{
Gregoria Mitropoulou ${ }^{1}$, Marianthi Sidira ${ }^{2}$, Myria Skitsa ${ }^{3}$, Ilias Tsochantaridis ${ }^{3}$, Aglaia Pappa ${ }^{3}$, \\ Christos Dimtsoudis ${ }^{2}$, Charalampos Proestos ${ }^{4}$ (D) and Yiannis Kourkoutas ${ }^{1, *(\mathbb{D})}$ \\ 1 Laboratory of Applied Microbiology and Biotechnology, Department of Molecular Biology \& Genetics, \\ Democritus University of Thrace, GR-68100 Alexandroupolis, Greece; gmitropo@mbg.duth.gr \\ 2 Research and Development Department, Macedonian-Thrace Brewery S.A., GR-69100 Komotini, Greece; \\ sidiramania@yahoo.gr (M.S.); dimtsoudis@vergina.com.gr (C.D.) \\ 3 Cellular and Molecular Physiology Research Group, Department of Molecular Biology \& Genetics, \\ Democritus University of Thrace, GR-68100 Alexandroupolis, Greece; myriaskitsa@hotmail.com (M.S.); \\ iliatsoc@gmail.com (I.T.); apappa@mbg.duth.gr (A.P.) \\ 4 Laboratory of Food Chemistry, Department of Chemistry, National and Kapodistrian University of Athens, \\ GR-15771 Athens, Greece; harpro@chem.uoa.gr \\ * Correspondence: ikourkou@mbg.duth.gr; Tel.: +30-25510-30633
}

Received: 8 May 2020; Accepted: 10 June 2020; Published: 1 July 2020

check for updates

\begin{abstract}
The aim of the present study was to investigate the antimicrobial potential of Sideritis raeseri subps. raeseri essential oil (EO) against common food spoilage and pathogenic microorganisms and evaluate its antioxidant and antiproliferative activity. The EO was isolated by steam distillation and analyzed by GC/MS. The main constituents identified were geranyl-p-cymene $(25.08 \%)$, geranyl- $\gamma$-terpinene (15.17\%), and geranyl-linalool (14.04\%). Initially, its activity against Staphylococcus aureus, Staphylococcus epidermidis, Escherichia coli, Listeria monocytogenes, Salmonella Enteritidis, Salmonella Typhimurium, Pseudomonas fragi, Saccharomyces cerevisiae, and Aspergillus niger was screened by the disk diffusion method. Subsequently, minimum inhibitory concentration (MIC), non-inhibitory concentration (NIC), and minimum lethal concentration (MLC) values were determined. Growth inhibition of all microorganisms tested was documented, although it was significantly lower compared to gentamycin, ciproxin, and voriconazole, which were used as positive controls. In a next step, its direct antioxidant properties were examined using 2,2-diphenyl-1-picrylhydrazyl (DPPH) and 2,2'-azino-bis(3-ethylbenzothiazoline-6-sulfonic acid) (ABTS) assays, and the $\mathrm{IC}_{50}$ values were determined. The potential cytoprotective activity of the oil against $\mathrm{H}_{2} \mathrm{O}_{2}$-induced oxidative stress and DNA damage was studied in human immortalized keratinocyte (HaCaT) cells using the comet assay. Finally, the antiproliferative activity of the oil was evaluated against a panel of cancer cell lines including A375, Caco2, PC3, and DU145 and the non-cancerous HaCaT cell line using the sulforhodamine $\mathrm{B}(\mathrm{SRB})$ assay, and the $\mathrm{EC}_{50}$ values were determined. The oil demonstrated weak radical scavenging activity, noteworthy cytoprotective activity against $\mathrm{H}_{2} \mathrm{O}_{2}$-induced oxidative stress and DNA damage in HaCaT cells, and antiproliferative activity against all cell lines tested, being more sensitive against the in vitro model of skin melanoma.
\end{abstract}

Keywords: Sideritis raeseri subsp. raeseri; essential oil; antimicrobial; antioxidant; antiproliferative activity 


\section{Introduction}

The use of natural compounds isolated by plant origins with biological activity (antimicrobial, antioxidant, and antiproliferative) has always been a topic of great interest [1-5]. The rising trend for bioactive substances witnessed today can be mainly attributed to the growing number and severity of food poisoning outbreaks worldwide along with the recent negative consumer perception against artificial food preservatives and the demand for novel functional foods with a health potential.

Among the various herbs, Sideritis, known as the "mountain" tea, is a controversial botanic genus with a complex taxonomical classification due to the high number of hybridizations that occur between species. It comprises more than 150 perennial and annual vegetal species and several subspecies [6]. It belongs to the Lamiaceae family and is well known for its use as herbal medicine, commonly as an herbal tea. Sideritis is abundant in Mediterranean regions, the Balkans, the Iberian Peninsula, and Macaronesia, but it can also be found in Central Europe and in Asia. In Greece, the most commonly cultivated species is Sideritis raeseri, distinguished in three main subspecies, Sideritis raeseri subsp. raeseri, Sideritis raeseri subsp. attica, and Sideritis raeseri subsp. florida [7].

Essential oils (EOs) are naturally occurring volatile compound mixtures isolated by plant material by different methods, including solvent extraction, supercritical fluid extraction, hydro distillation, and steam distillation. Selection of the extraction method is crucial, since extraction yield and volatile composition depend greatly on the conditions applied. Distillation-based processes are considered advantageous due to flexibility, versatility, avoidance of volatile compounds decomposition, and ability for wide volume range operations, but the extraction yields may vary highly upon time, pressure, and temperature [8], as previously recorded for Sideritis raeseri subsp. raeseri EOs [9,10]. Likewise, remarkable differences on its chemical composition have been reported [7,9,10], which could be attributed to variations on extraction/isolation methods, plant chemotypes, harvesting periods, environment and climate, as well as improper taxonomical classification [11].

Despite the fact that a series of pharmacological activities such as antimicrobial, antioxidant, anti-inflammatory, and antiproliferative action of various extracts and oils isolated by several Sideritis spp. have been previously published [9,11-13], the biological activity of S. raeseri subsp. raeseri EO has been scarcely studied. In particular, no inhibitory action of $S$. raeseri subsp. raeseri EO against common food spoilage microorganisms, such as Staphylococcus epidermidis, Pseudomonas fragi, Saccharomyces cerevisiae, Aspergillus niger, etc. [14-16], and pathogens associated with food poisoning outbreaks worldwide, such as Staphylococcus aureus, Escherichia coli, Listeria monocytogenes, Salmonella spp., etc. [17], has been reported, although the antimicrobial activity of wide range of Sideritis spp. EOs and extracts has been tested [11]. There are also few reports on the antioxidant or other biological activities of various extracts or isolated compounds of plant preparations of S. raeseri species [13], but no information on EO preparations from $S$. raeseri subsp. raeseri exists.

Hence, the aim of the present study was to investigate the antimicrobial potential of $S$. raeseri subsp. raeseri $\mathrm{EO}$ against common food spoilage and pathogenic microorganisms and evaluate its antioxidant and antiproliferative activity, in order to assess potential commercial applications in food and pharmaceutical industries.

\section{Materials and Methods}

\subsection{Standard Compounds}

Standard compounds used for identification in GC/MS analysis were kindly provided by Professor L. Skaltsounis, Department of Pharmacy, National and Kapodistrian University of Athens, Athens, Greece. n-Pentane (Merck, Darmstadt, Germany) for spectroscopy (Uvasol ${ }^{\circledR}$ ) was used for the dilution of EOs analyzed by GC-MS. The alkane C10-C40 analytical standard mixture was obtained from Sigma-Aldrich (Sigma-Aldrich, Darmstadt, Germany). 


\subsection{Plant Material}

S. raeseri subsp. raeseri plant was cultivated in 2014 at Vrinena region of the Othrys mountain in Greece. The aerial parts of the plants were collected and air-dried naturally at temperature ranging $25-27^{\circ} \mathrm{C}$ during the daytime and $16-22{ }^{\circ} \mathrm{C}$ during the night for $7-8$ days.

\subsection{Extraction of EO}

EO was produced by steam distillation for $75 \mathrm{~min}$ using dried herb of $S$. raeseri subsp. raeseri (20 kg dry weight). The obtained EO $(5 \mathrm{~mL})$ was dried over anhydrous sodium sulfate and kept in a sealed vial at $4{ }^{\circ} \mathrm{C}$. The yield $(w / w)$ was $0.025 \%$ (on a dry weight basis).

\subsection{Microbial Strains}

Staphylococcus aureus ATCC 25923, Staphylocccus epidermidis FMCC B-202 C5M6 (kindly provided by Dr. A. Nisiotou, Athens Wine Institute, ELGO-DEMETER, Greece), Escherichia coli ATCC 25922, Listeria monocytogenes NCTC 10527 serotype 4b, Salmonella enterica subsp. enterica ser. Enteritidis FMCC B56 PT4 (kindly provided by Professor G.J.E. Nychas, Agricultural University of Athens, Greece), and Salmonella enterica subsp. enterica ser. Typhimurium DSMZ 554 were grown in Brain Heart Infusion (BHI) broth (LABM, Heywood, UK) at $37^{\circ} \mathrm{C}$ for $24 \mathrm{~h}$. Pseudomonas fragi 211 (kindly provided by Professor G.J.E. Nychas) was grown in BHI broth (LABM) at $25^{\circ} \mathrm{C}$ for $24 \mathrm{~h}$. Saccharomyces cerevisiae uvaferm NEM (Lallemand, Montreal, QC, Canada) was grown in YPD broth (yeast extract $10 \mathrm{~g} / \mathrm{L}$, peptone $20 \mathrm{~g} / \mathrm{L}$, and dextrose $20 \mathrm{~g} / \mathrm{L}$ ) at $28^{\circ} \mathrm{C}$ for 3 days. Aspergillus niger 19111 (kindly provided by Professor G.J.E. Nychas) was grown on Malt extract agar (LABM) for 7 days at $37^{\circ} \mathrm{C}$.

\subsection{Analytical Procedures}

\subsubsection{GC/MS}

EO was diluted with $n$-pentane at a concentration of $2 \mathrm{mg} / \mathrm{mL}$, and $1 \mu \mathrm{L}$ was injected to the GC/MS (in splitless mode). The analysis was performed in triplicate using Finnigan Trace GC Ultra 2000/Finnigan Trace DSQ MSD (Thermo Electron Corporation, Waltham, MA, USA) operating in EI mode. The separation was performed on a Trace TR-5MS (Thermo Scientific, Waltham, MA, USA) ( $30 \mathrm{~m} \times 0.25 \mathrm{~mm}, 0.25 \mu \mathrm{m}$ film thickness) capillary column. He at a flow rate of $0.8 \mathrm{~mL} / \mathrm{min}$ was used as carrier gas. The initial temperature of the column was set at $60^{\circ} \mathrm{C}$, and then it was heated to $240{ }^{\circ} \mathrm{C}$ at a rate of $3{ }^{\circ} \mathrm{C} / \mathrm{min}$ for $10 \mathrm{~min}$. The injector temperature was kept at $200^{\circ} \mathrm{C}$. The detector voltage was $70 \mathrm{eV}$, and the temperature was $250^{\circ} \mathrm{C}$. Identification of the compounds was carried out by comparing the retention times and the mass spectra of volatiles to ADAMS, Wiley275, NIST, and in-house created libraries and by determining Kovats' retention indexes (KI) using $n$-alkanes (C10-C40) and comparing them with those reported in the literature.

\subsubsection{Antimicrobial Assays}

Screening of S. raeseri subp. raeseri EO Antimicrobial Activity by the Disc Diffusion Assay

The antimicrobial activity of the Sideritis raeseri subsp. raeseri EO was initially tested using the disk diffusion assay, as described previously by Mitropoulou et al. [18], using gentamycin (10 mg) (Oxoid Ltd., Basingstoke, UK) as positive control and sterile water as negative.

A similar procedure was also followed for screening the activity against yeasts and molds, using S. cerevisiae and A. niger as model microorganisms [18]. Voriconazole (1 $\mathrm{mg})$ (BioRad Laboratories Inc., Hercules, CA, USA) was used as positive control and sterile water as negative.

Determination of Minimum Inhibitory), Non-Inhibitory, and Minimum Bactericidal Concentrations

Determination of minimum inhibitory concentration (MIC) and non-inhibitory concentrations (NIC) was carried out, as recently described by Mitropoulou et al. [18], by monitoring changes in 
optical density of bacterial suspensions in BHI broths containing multiple concentrations (ranging from $41-8786 \mathrm{mg} / \mathrm{L}$ ) of the EO at $610 \mathrm{~nm}$ using a microplate reader (Molecular Devices, VERSAmax, San Jose, California, USA, Softmaxprov.5.0 software) during incubation at $37^{\circ} \mathrm{C}$ for $24 \mathrm{~h}$ for all bacteria species, except $P$. fragi, which was incubated at $25^{\circ} \mathrm{C}$. Ciproxin and gentamycin were used as positive controls, and BHI broths with no inoculum and inoculated BHI broths with no essential oil were used as negative controls.

The calculation of MIC and NIC values was based on the Lambert-Pearson model (LPM) $[19,20]$.

As the LPM model was not applicable to $S$. cerevisiae and A. niger due to yeast cell sedimentation and conidia flotation, the standard protocols described by The European Committee on Antimicrobial Susceptibility Testing (EUCAST) were applied for MIC determination [21,22], using voriconazole as positive control [23,24].

Minimum lethal concentration (MLC) was determined, as previously described by Mitropoulou et al. [18].

All experiments were carried out at least in four replicates.

\subsection{Assessment of Cell-Free Antioxidant Activity by DPPH and ABTS Assays}

The radical scavenging activity of $S$. raeseri subsp. raeseri $\mathrm{EO}$ was determined by the colorimetric 2,2-diphenyl-1-picrylhydrazyl (DPPH) and 2,2'-Azino-bis(3-ethylbenzothiazoline-6-sulfonic acid) (ABTS) assays $[25,26]$, as previously described. Serial dimethylsulfoxide (DMSO) solutions of EO concentration ranging from 0.0042 to $42 \mathrm{mg} / \mathrm{mL}$ were prepared. Samples $(10 \mu \mathrm{L})$ were mixed with DPPH or ABTS solution ( $200 \mu \mathrm{L}$ total volume) in a 96-well plate and then incubated for $30 \mathrm{~min}$ in the dark (RT). Inhibition of formation of the radicals was monitored by measuring absorbance at $492 \mathrm{~nm}$ (DPPH assay) or $734 \mathrm{~nm}$ (ABTS assay) using a microplate reader (EnSpire Multimode Plate Reader, PerkinElmer, Waltham, MA, USA). The inhibition percentage of the radicals for each dilution was calculated as described previously [27]. Ascorbic acid was used as positive control. Based on the values derived from the inhibition percentage of each radical, reference curves were made for $S$. raeseri subsp. raeseri $\mathrm{EO}$, from which the $\mathrm{IC}_{50}$ values $(\mathrm{mg} / \mathrm{mL}$ ) were calculated (EO concentration-inhibition percentage) by regression analysis using Sigma Plot Software v.10 (Systat Software Inc., San Jose, CA, USA). All determinations were performed in triplicates.

\subsection{Sulforhodamine B Assay (SRB)}

The antiproliferative effect of $S$. raeseri subsp. raeseri $\mathrm{EO}$ was evaluated by the SRB assay as previously described by Fitsiou et al. [27]. For this assay, $3 \times 10^{3}$ human immortalized keratinocyte (HaCaT) and A375 cells and $4 \times 10^{3} \mathrm{PC} 3$, DU145, and Caco2 were cultured in 96-well microplates for $24 \mathrm{~h}$ and then treated with various concentrations of $S$. raeseri subsp. raeseri $\mathrm{EO}(0-0.84 \mathrm{mg} / \mathrm{mL})$ for 72 h. Cell viability curves were plotted, and the $\mathrm{EC}_{50}$ values corresponding to efficient concentrations of $S$. raeseri subsp. raeseri $\mathrm{EO}$ required to cause $50 \%$ decrease in cell viability were determined by regression analysis using Sigma Plot Software v.10.

\subsection{Single Cell Gel Electrophoresis (comet) Assay}

Single cell gel electrophoresis (comet) assay was performed as described previously [28,29]. Briefly, HaCaT cells $\left(2 \times 10^{4}\right)$ were treated with $S$. raeseri subsp. raeseri $\mathrm{EO}(0.05 \mathrm{mg} / \mathrm{mL}$ and $0.5 \mathrm{mg} / \mathrm{mL})$ for 20 min followed by incubation with $\mathrm{H}_{2} \mathrm{O}_{2}(50 \mu \mathrm{M})$ for $20 \mathrm{~min}$ in phosphate buffered saline (PBS) or left untreated or treated with $\mathrm{EO} / \mathrm{H}_{2} \mathrm{O}_{2}$ alone for $20 \mathrm{~min}$. Then, cells were embedded in low-melting agarose on microscope slides and processed for monitoring DNA damage levels by applying the alkaline version of the comet assay, which detects both single- and double-strand DNA breaks. Slides were observed by fluorescence microscopy (Zeiss Axio Scope.A1, Oberkochen, Germany). Image analysis and scoring of DNA damage in arbitrary units (AU) was performed as previously described by Panayiotidis et al. [30]. Results were expressed as fold-change relative to control. 


\subsection{Statistical Analysis}

The mean values are presented, and standard deviation in MIC and NIC values determined by the Lambert-Pearson model (LPM) was calculated by Figure P.2.1 software (Fig.P Software Incorporated, Hamilton, ON, Canada).

The results were analyzed with analysis of variance (ANOVA) using Duncan's multiple range test to determine significant differences $(p<0.05)$ among results (coefficients, ANOVA tables, and significance $(p<0.05)$ were computed using Statistica software (v.10.0, StatSoft, Tulsa, USA).

\section{Results and Discussion}

\subsection{GC/MS Analysis}

A significantly low oil extraction yield $(0.025 \%)$ compared to a previous study was recorded [9], probably due to the lower time allowed for steam distillation (75 min in contrast to $3 \mathrm{~h}$ usually applied) $[8,9]$. A short distillation process was decided to avoid decomposition and chemical changes of the major constituents, as time is a crucial factor affecting the quality of the distilled EO [8]. However, similar or even lower extraction yields have been previously reported for various Sideritis species $[8,31,32]$.

The main constituents of $S$. raeseri subsp. raeseri $\mathrm{EO}$ were determined by GC/MS. The results are presented in Table 1, and a typical chromatogram is shown in Figure 1. In total, 19 compounds were identified. Geranyl-p-cymene (25.08\%), geranyl- $\gamma$-terpinene (15.17\%), and geranyl-linalool $(14.04 \%)$ were the main compounds detected, accounting for approximately $54 \%$ of the total area. Of note, GC/MS analysis provided data about the content percentage of the volatile compounds and not their actual concentration.

Table 1. GC/MS analysis of Sideritis raeseri subsp. raeseri essential oil.

\begin{tabular}{|c|c|c|c|}
\hline RT (min) & Component Name & MS Fragments & Area $(\%)$ \\
\hline 6.11 & $\alpha$-Pinene & $\begin{array}{c}136(\mathrm{MW}), 121,105,93,92,91,77,41 \\
39,27\end{array}$ & 2.13 \\
\hline 7.53 & $\beta$-Pinene & $\begin{array}{c}136(\mathrm{MW}), 121,93,91,79,77,69,41 \\
39,27\end{array}$ & 2.31 \\
\hline 9.20 & 1,3,8-p-Menthatriene & $134(\mathrm{MW}), 119,91$ & 2.67 \\
\hline 18.78 & 1,1,6-Trimethyl-tetralin & $174(\mathrm{MW}), 159,131,115$ & 0.43 \\
\hline 21.20 & Carvacrol & $150(\mathrm{MW}), 135,91$ & 0.93 \\
\hline 23.91 & $\beta$-Copaene & $204(\mathrm{MW}), 161,119,105,93$ & 0.72 \\
\hline 25.81 & caryophyllene & $\begin{array}{c}204(\mathrm{MW}), 189,175,161,147,133,120 \\
105,93,91,79,69,41\end{array}$ & 2.88 \\
\hline 28.96 & $\gamma$-Elemene & 204(MW), 161, 121, 107, 93 & 5.73 \\
\hline 29.36 & $\alpha$-Bisabolene & $204(\mathrm{MW}), 121,119,109,93$ & 1.56 \\
\hline 29.80 & $(+)$ - $\delta$-Cadinene & $204(\mathrm{MW}), 189,161,134,119,105,81,41$ & 0.60 \\
\hline 30.03 & Cadina-1,3,5-triene & $202(\mathrm{MW}), 187,159,144,129,115,105$ & 3.25 \\
\hline 32.31 & (-)-Spathulenol & 220 (MW), 205, 187, 159, 105, 91 & 2.82 \\
\hline 32.49 & Caryophyllene oxide & $\begin{array}{c}220 \text { (MW), 205, 177, 161, 149, 135, 121 } \\
109,93,79,43,41\end{array}$ & 1.24 \\
\hline 36.32 & $\alpha$-Bisabolol & $\begin{array}{c}204 \text { (MW), 189, 161, 139, 119, 109, 93, 69, } \\
43,41\end{array}$ & 2.90 \\
\hline 41.58 & $(2 \mathrm{E}, 6 \mathrm{E})$-Farnesyl acetate & $\begin{array}{c}264 \text { (MW), 204, 161, 138, 123, 107, 93, 69, } \\
43,41\end{array}$ & 3.59 \\
\hline 44.03 & Geranyl-linalool & $\begin{array}{c}290(\mathrm{MW}), 272,203,161,147,135,119 \\
107,93,81,69,41\end{array}$ & 14.04 \\
\hline 44.32 & $\begin{array}{c}\text { (6E,10E)-7,11,15-Trimethyl-3-methylene- } \\
\text { 1,6,10,14-hexadecatetrene }\end{array}$ & 272 (MW), 148, 132, 109, 93, 69, 41 & 1.54 \\
\hline 45.37 & Geranyl-p-cymene & 242 (MW), 134, 119, 91 & 25.08 \\
\hline 45.71 & Geranyl- $\gamma$-terpinene & $272(\mathrm{MW}), 136,121,93,91,77$ & 15.17 \\
\hline
\end{tabular}




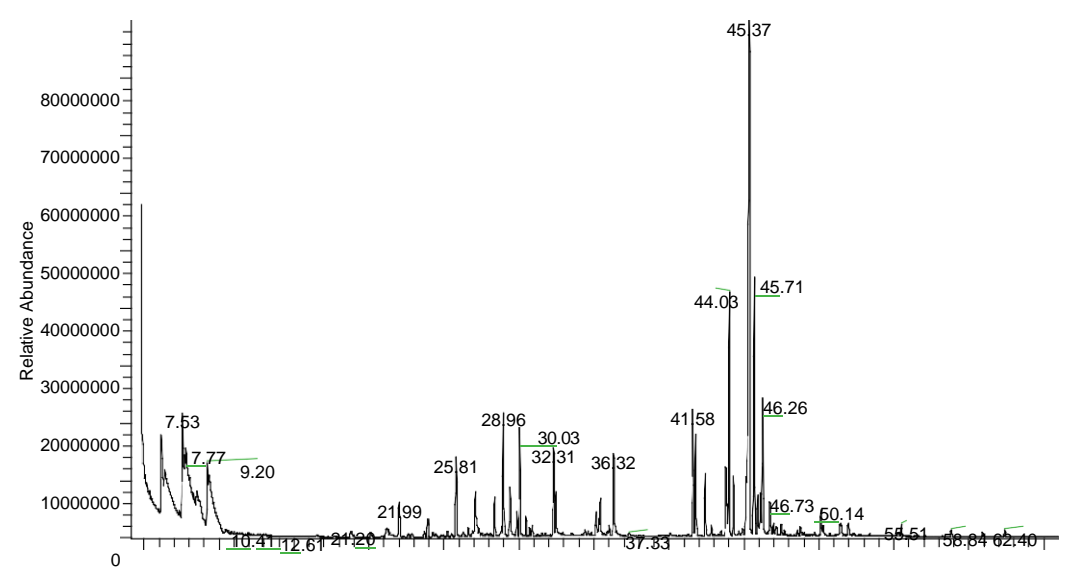

Figure 1. A typical GC/MS chromatogram of Sideritis raeseri subsp. raeseri essential oil.

Our results are in contradiction with previous studies $[7,9,10]$. Specifically, the Sideritis raeseri subsp. raeseri oil isolated by Alligiannis et al. [9] was characterized by the presence of $\beta$-pinene $(9.06 \%)$, AR-curcumene (6.14\%), $\beta$-phellandrene/limonene (6.06\%), $\delta$-cadinene $(4.83 \%), \beta$-caryophyllene $(4.17 \%)$, and $\alpha$-copaene (3.80\%), while Koedam et al. [10] reported that the major constituents of the S. raeseri subsp. raeseri oil isolated by circulatory distillation were $\beta$-pinene $(20.61 \%), \alpha$-pinene $(16.50 \%)$, $\alpha$-humulene (9.91\%), limonene (6.73\%), $\beta$-caryophyllene (6.52\%), and D-germacrene (5.52\%). However, compounds with similar structure to compounds identified in our study, such as 9-geranyl- $\alpha$-terpinene and 9-geranyl-p-cymene, were found in Sideritis dichotoma oil [32]. Of note, 9-geranyl-p-cymene was also identified as a major constituent in Sideritis trojana oil [31]. These differences might be due to difficulties in proper taxonomical classification, as well as in differentiations in isolation/extraction methods, plant and location origin, climate and environmental conditions, time of harvesting, etc, that affect significantly the chemical composition $[6,11,33]$. In addition, the existence of more than one chemotype or ecotype of $S$. raeseri ssp. raeseri should not be excluded.

\subsection{Antimicrobial Assays}

The antimicrobial activity of $S$. raeseri subsp. raeseri $\mathrm{EO}$ was evaluated against a list of common food spoilage and pathogenic microorganisms [4,14-17], consisting of Staphylococcus aureus, Staphylococcus epidermidis, Escherichia coli, Listeria monocytogenes, Salmonella Enteritidis, Salmonella Typhimurium, Pseudomonas fragi, Saccharomyces cerevisiae, and Aspergillus niger. The presence of Escherichia coli, Listeria, and Salmonella spp. in foods is a primary concern due to their implication in a number of food poisoning outbreaks worldwide [17]. Similarly, food quality and safety is directly related to staphylococci counts, as its presence in high numbers constitutes a health hazard and results in spoilage [14]. Likewise, Pseudomonas fragi is a psychrotrophic bacteria associated mainly with food spoilage during storage at low temperatures [15]. Saccharomyces cerevisiae and Aspergillus niger are the usual cause of soft drinks and both alcoholic and non-alcoholic beverages [16] and served as model systems [34,35].

The effectiveness of the oil was initially confirmed using the disk diffusion method (data not shown). Subsequently, MIC and NIC values against were assessed, because their precise determination is crucial for food and pharmaceutical industries in order to regulate the optimum amount of the antimicrobial agent to secure microbial safety. MIC and NIC for bacteria were determined using a previously published model [19], combining the absorbance measurements with the common dilution method and non-linear regression analysis to fit the data, while the corresponding MIC values for S. cerevisiae and $A$. niger were estimated by standard protocols [21,22]. The effective growth inhibition of $S$. raeseri subsp. raeseri $\mathrm{EO}$ against all microorganisms tested (Table 2) was documented, although MIC, NIC, and MLC values were significantly $(p<0.05)$ higher compared to ciproxin, gentamycin, and voriconazole $[18,27]$, which were used as positive controls. 
Table 2. Minimum inhibitory concentration (MIC), non-inhibitory concentration (NIC), and minimum lethal concentration (MLC) (mg/L) of Sideritis raeseri subsp. raeseri essential oil (EO) against common food spoilage and pathogenic microorganisms. Lambert-Pearson (LPM) model was not applicable to S. cerevisiae and A. niger due to yeast cell sedimentation and conidia flotation. Thus, determination of MIC values was based on the standard protocols described by EUCAST [21,22].

\begin{tabular}{|c|c|c|c|c|c|c|c|c|c|c|c|c|}
\hline \multirow{2}{*}{ Microbial Species } & \multicolumn{3}{|c|}{ S. raeseri subsp. raeseri EO } & \multicolumn{3}{|c|}{$\begin{array}{l}\text { Ciproxin (Data Reproduced by } \\
\text { Fitsiou et al. (2016) [27] }\end{array}$} & \multicolumn{3}{|c|}{$\begin{array}{l}\text { Gentamycin (Data Reproduced by } \\
\text { Mitropoulou et al. (2017) [18] }\end{array}$} & \multicolumn{3}{|c|}{ Voriconazole } \\
\hline & MIC * & NIC * & MLC ** & MIC * & NIC* & MLC ** & MIC * & NIC* & MLC ** & MIC* & NIC* & MLC ** \\
\hline Staphylococcus aureus & $7116 \pm 26$ & $5887 \pm 35$ & 31630 & $0.982 \pm 0.002$ & $0.963 \pm 0.003$ & 4 & $3.332 \pm 0.003$ & $3.021 \pm 0.001$ & 16 & - & - & - \\
\hline Staphylococcus epidermidis & $7732 \pm 35$ & $5535 \pm 35$ & 30751 & $0.979+0.002$ & $0.957+0.002$ & 4 & $3.421 \pm 0.001$ & $3.127 \pm 0.001$ & 16 & - & - & - \\
\hline Escherichia coli & $6414 \pm 26$ & $5974 \pm 26$ & 26358 & $0.984+0.001$ & $0.956 \pm 0.002$ & 4 & $3.952 \pm 0.001$ & $3.253 \pm 0.002$ & 16 & - & - & - \\
\hline Listeria monocytogenes & $6853 \pm 35$ & $5799 \pm 44$ & 28115 & $0.979 \pm 0.001$ & $0.968+0.001$ & 4 & $3.121 \pm 0.002$ & $3.001 \pm 0.002$ & 16 & - & - & - \\
\hline Salmonella Enteritidis & $6326 \pm 44$ & $5799 \pm 26$ & 26358 & $0.976 \pm 0.001$ & $0.957 \pm 0.001$ & 8 & $4.942 \pm 0.001$ & $4.011 \pm 0.001$ & 18 & - & - & - \\
\hline Salmonella Typhimurium & $5974 \pm 26$ & $5447 \pm 53$ & 26358 & $0.979 \pm 0.001$ & $0.964 \pm 0.001$ & 8 & $4.211 \pm 0.002$ & $4.026 \pm 0.001$ & 18 & - & - & - \\
\hline Pseudomonas fragi & $5184 \pm 35$ & $4305 \pm 26$ & 21965 & $0.955 \pm 0.001$ & $0.940 \pm 0.002$ & 8 & $4.134 \pm 0.002$ & $4.009 \pm 0.002$ & 18 & - & - & - \\
\hline S. cerevisiae & 7029 & - & 28115 & - & - & - & - & - & - & 0.25 & - & 1.00 \\
\hline A. niger & 8786 & - & 35144 & - & - & - & - & - & - & 0.50 & - & 2.00 \\
\hline
\end{tabular}

* Results are shown as mean \pm SD when applicable. ${ }^{* *}$ Standard deviation for MLC ranged in zero values. 
Although similar results reporting remarkable antimicrobial activity of EOs or methanol and aqueous extracts isolated by various Sideritis spp. were previously reported [9,11,12], EO derived from $S$. raeseri subsp. raeseri had no inhibitory effect when tested against a series of spoilage and pathogenic microorganisms, such as S. aureus, S. epidermidis, P. aeruginosa, E. cloacae, K. pneumonia, E. coli, C. albicans, C. tropicalis, or T. glabrata [9], in contrast to our results. These findings highlight that chemical composition of the EOs and thus their biological activity may vary greatly depending on a high number of factors [11]. Hence, to the best of our knowledge, this is the first report estimating MIC and NIC values for $S$. raeseri subsp. raeseri $\mathrm{EO}$, applying a reliable, rapid, and efficient method based on the LPM model $[19,20]$. Despite the fact that no antimicrobial action has been correlated to the main components of the $S$. raeseri subsp. raeseri $\mathrm{EO}$ separately, its activity could be attributed to all constituents, and possible synergistic effects should not be excluded.

\subsection{Determination of Radical Scavenging Activity}

To investigate the potential anti-oxidant potential of S. raeseri subsp. raeseri $\mathrm{EO}$, we studied the in vitro radical scavenging activity by utilizing the $\mathrm{DPPH} \bullet$ and the $\mathrm{ABTS} \bullet^{+}$radical scavenging assays. The $\mathrm{IC}_{50}$ value of the $S$. raeseri subsp. raeseri $\mathrm{EO}$, corresponding to the sample concentration required to scavenge radicals by $50 \%$, was estimated to be $24.77 \pm 4.21$ and $1.27 \pm 0.59 \mathrm{mg} / \mathrm{mL}$ in the cases of DPPH• and ABTS $\bullet^{+}$assays, respectively (Table 3). Ascorbic acid (potent antioxidant agent) was used as a positive control. Low $\mathrm{IC}_{50}$ values indicate strong antioxidant activities. Compared to ascorbic acid, the $S$. raeseri subsp. raeseri $\mathrm{EO}$ possesses weak in vitro antioxidant capacity. This is the first time reporting on the direct in vitro antioxidant activity of the $S$. raeseri subsp. raeseri $\mathrm{EO}$ preparation. To our best knowledge, there is no available information about the antioxidant potential of its major compounds (geranyl-p-cymene, geranyl- $\gamma$-terpinene, and geranyl-linalool).

Table 3. Antioxidant activity of $S$. raeseri subsp. raeseri essential oil in vitro.

\begin{tabular}{ccc}
\hline \multicolumn{2}{c}{ IC $_{50}(\mathrm{mg} / \mathrm{mL})$} \\
& DPPH Assay & ABTS Assay \\
\hline S. raesaeri & $24.77 \pm 4.21$ & $1.27 \pm 0.59$ \\
Ascorbic acid ${ }^{* *}$ & $0.012 \pm 0.004$ & $0.0045 \pm 0.0002$ \\
\hline * Results are shown as mean \pm SD. ${ }^{* *}$ Ascorbic acid was used as positive control.
\end{tabular}

Additionally, limited literature information exists on the antioxidant activity of EO preparations of other Sideritis spp. Antioxidant, anticholinesterase, and anti-tyrosinase activities of the EOs of Sideritis albiflora and Sideritis leptoclada have been reported, and those preparations characterized by high concentrations of phenolic and flavonoid contents indicated the highest antioxidant and enzyme inhibitory activities [36]. In a follow-up study, the acetone extracts showed the highest activity in terms of antioxidant activity of both Sideritis species, while the hexane extracts exhibited superior urease inhibitory activity. Both species were found to be rich in rosmarinic and caffeic acids [37].

Previous studies on different parts of plant extracts of Sideritis spp. demonstrated antioxidant activity for methanolic/etnanolic or aqueous extracts measured similarly by DPPH $\bullet$ or ABTS $\bullet{ }^{+}$assays, which was the weakest amongst 24 extracts from Greek domestic Lamiaceae species. Moderate antioxidant activity was reported for a methanolic extract of the aerial parts of the plant Sideritis raeseri subsp. raeseri estimated by $\mathrm{Co}$ (II) ethylenediaminetetraacetic acid (EDTA)-induced luminol chemiluminescence and DPPH• scavenging assay. The extract comprised nine 7-o-allosyl glucosides of 5,8-dihydroxy substituted flavones [38]. In most cases, the anti-oxidant effects reported for the samples studied were related to the total phenolic or flavonoid content of the extract preparations. 
3.4. S. raeseri subsp. raeseri EO Protects Human Epidermal Keratinocytes ( $\mathrm{HaCaT}$ ) Cells from $\mathrm{H}_{2} \mathrm{O}_{2}$-Induced DNA Damage

Our previous results indicated that the $S$. raeseri subsp. raeseri EO possesses weak antioxidant activity using direct in vitro radical scavenging assays. However, the application of in vitro cell-based assays offers various advantages towards more accurately, accessing the antioxidant effects of tested compounds at a subcellular level. Cell-based assays can be more advantageous in the way that they may reveal more information about the antioxidant capacity of compounds that may trigger cell antioxidant mechanisms without direct radical scavenging action [39]. For this reason, we next explored the potential cytoprotective effect of $S$. raeseri subsp. raeseri $\mathrm{EO}$ against $\mathrm{H}_{2} \mathrm{O}_{2}$-induced DNA damage. Hydrogen peroxide is a non-radical derivative of oxygen with physiological significance as an oxidative agent; it is soluble, present in all biological systems, and capable of cell death induction [39]. Human keratinocytes (HaCaT) were pre-incubated in the presence or the absence of $\mathrm{EO}(0.05$ and 0.5 $\mathrm{mg} / \mathrm{mL}$ for $20 \mathrm{~min}, \mathrm{RT})$ and treated with $\mathrm{H}_{2} \mathrm{O}_{2}(100 \mu \mathrm{M})$ for $20 \mathrm{~min}$ to induce cellular oxidative DNA damage. DNA damage was monitored as single- and double-strand breaks in DNA by employing the alkaline version of single cell gel electrophoresis (comet) assay. The results are represented in Figure 2. Incubation of the HaCaT cells with the $S$. raeseri subsp. raeseri $\mathrm{EO}$ alone slightly caused a significant increase in DNA damage levels only in the case of the highest concentration of the EO used $(0.5 \mathrm{mg} / \mathrm{mL})$ (approximately 1.2-fold compared to untreated cells). Treatment of HaCaT cells with $\mathrm{H}_{2} \mathrm{O}_{2}$, significantly induced DNA damage levels (> 2.5-fold) compared to control. In the case of cell pretreatment with the two different concentrations of $S$. raeseri subsp. raeseri $\mathrm{EO}$, the DNA damage observed was significantly lower and dose-dependent. More particularly, pre-treatment of $\mathrm{HaCaT}$ cells with $0.05 \mathrm{mg} / \mathrm{mL}$ or $0.5 \mathrm{mg} / \mathrm{mL}$ S. raeseri subsp. raeseri EO caused $34 \%$ and $44 \%$ decrease in the $\mathrm{H}_{2} \mathrm{O}_{2}$-induced DNA damage levels, respectively.

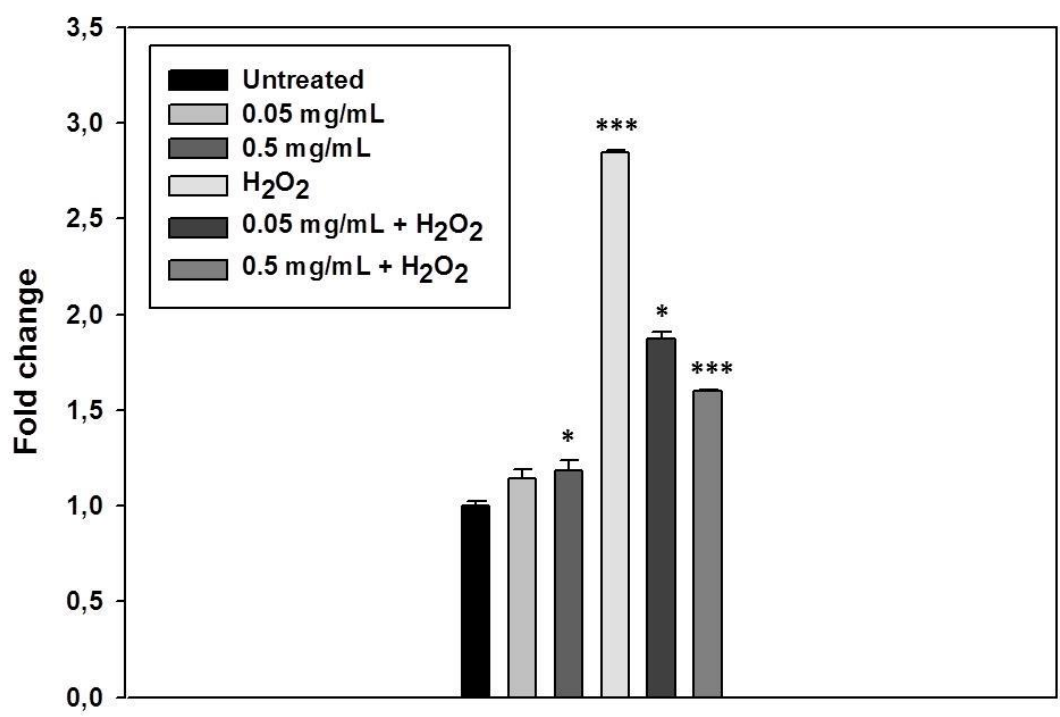

Figure 2. Cytoprotective activity of $S$. raeseri subsp. raeseri essential oil against $\mathrm{H}_{2} \mathrm{O}_{2}$-induced DNA damage on human immortalized keratinocyte $(\mathrm{HaCaT})$ cells. HaCaT cells were incubated with $S$. raeseri subsp. raeseri essential oil $(0.05 \mathrm{mg} / \mathrm{mL}$ and $0.5 \mathrm{mg} / \mathrm{mL})$ for $20 \mathrm{~min}$ and then $20 \mathrm{~min}$ with $\mathrm{H}_{2} \mathrm{O}_{2}$ both in presence and in absence of the oil. Comet assay was performed to assess the $\mathrm{H}_{2} \mathrm{O}_{2}$-induced DNA damage. The data presented are the mean $\pm \mathrm{SD}$ of three independent experiments performed in triplicates. ${ }^{*} p<0.05,{ }^{* * *} p<0.001$ vs. untreated.

Previously, González-Burgos et al. [40] demonstrated the cytoprotective role of other species of Sideritis spp. on PC12 and U373-MG cells. They indicated that pre-treatment with isolated diterpenoids from Sideritis spp. prevented the $\mathrm{H}_{2} \mathrm{O}_{2}$-induced mitochondrial membrane disorder. Further studies 
are required to investigate the potential protective role of the $\mathrm{EO}$ against oxidative stress and the underlying mechanism(s) of action.

\subsection{Determination of Antiproliferative Activity}

Next, we evaluated the antiproliferative effect of the EO in various cancer cell lines. For this purpose, we utilized human melananoma A375, human colon adenosarcoma Caco2, and human prostate carcinoma cell lines PC3 and DU145. Moreover, a non-cancerous human cell line, the human keratinocytes $\mathrm{HaCaT}$, was also employed in the study to discrete for preferential cancer-specific antiproliferative activity amongst the cell lines. Overall, cells were treated with increasing concentrations of $S$. raeseri subsp. raeseri $\mathrm{EO}$ for $72 \mathrm{~h}$, and then cell viability was assessed as percent of control, and the corresponding $\mathrm{EC}_{50}$ value was also determined. As shown in Table 4, the observed patterns of antiproliferative activity were very similar between all the cell lines, and the $\mathrm{EC}_{50}$ value ranged approximately from $0.114-0.216 \mathrm{mg} / \mathrm{mL}$. To our best knowledge, there is no available information about the antiproliferative/anticancer potential of its major compounds (geranyl-p-cymene, geranyl- $\gamma$-terpinene, and geranyl-linalool).

Table 4. Antiproliferative activity of S. raeseri subsp. raeseri essential oil against different cell lines.

\begin{tabular}{cc}
\hline Cell Line & EC $_{\mathbf{5 0}}(\mathbf{m g} / \mathbf{m L}) *$ \\
\hline A375 & $0.151 \pm 0.008$ \\
HaCaT & $0.114 \pm 0.015$ \\
Caco2 & $0.175 \pm 0.080$ \\
PC3 & $0.216 \pm 0.090$ \\
DU145 & $0.188 \pm 0.060$ \\
\hline
\end{tabular}

${ }^{*}$ Results are shown as mean $\pm \mathrm{SD}$.

Few studies have investigated the antiproliferative potential of Sideritis spp. Tóth et al. [41] examined the antiproliferative effects of isolated diterpenoids derived from Sideritis montana on human cancer cell lines (HeLa, SiHa, and C33A) by using MTT assay. Moreover, Tadić et al. [42] investigated the cytotoxic effect of Sideritis scardica on PBMC, B16, and HL-60 cells, demonstrating also the potential anti-inflammatory effects of that extract.

\section{Conclusions}

The use of EOs as natural antimicrobial, antioxidant, and antiproliferative agents is less explored compared to their utilization as food flavorings and, thus, their application in food and pharmaceutical industries is limited. Our results revealed the growth inhibitory action of $S$. raeseri subsp. raeseri $\mathrm{EO}$ against food spoilage and pathogenic microoganisms, although its activity was significantly lower than gentamycin, ciproxin, and voriconazole that were used as positive controls, indicating that it represents a source of natural antimicrobial agent, which may be incorporated in food products to prevent spoilage and assure microbial safety. Furthermore, the oil exhibited low antioxidant activity by directly scavenging radicals. However, it indicated promising cytoprotective activity against $\mathrm{H}_{2} \mathrm{O}_{2}$-induced oxidative stress and DNA damage in $\mathrm{HaCaT}$ cells, suggesting the exertion of non-direct antioxidant mechanisms that require further exploration. Finally, the antiproliferative activity of the EO was evaluated against a panel of cell lines. It showed similar activity against all cell lines tested being more sensitive against the in vitro model of skin melanoma. However, similar activity was also observed against the non-carcinoma cell line $\mathrm{HaCaT}$, indicating that it may not possess cancer-specific antiproliferative activity, although further studies are required. Although main components of the EO have been reported as main constituents in other plant extracts with similar biological activities [43-45], there are no available studies on the biological activities of the individual compounds, which is a valid area of further investigation. Overall, the results of our study indicated that EO form S. raeseri 
subsp. raeseri has favorable biological properties that may have potential applications in food and pharmaceutical industries.

Author Contributions: Conceptualization, A.P. and Y.K.; data curation, I.T., A.P., C.P., and Y.K.; funding acquisition, A.P.; investigation, G.M., M.S. (Marianthi Sidira), M.S. (Myria Skitsa), I.T., and C.P.; methodology, G.M., M.S. (Myria Skitsa), I.T., and C.P.; project administration, A.P. and Y.K.; resources, A.P., C.D., and Y.K.; supervision, A.P., C.D., and Y.K.; validation, A.P. and C.P.; visualization, A.P.; writing-original draft, G.M., M.S. (Marianthi Sidira), I.T., M.S. (Myria Skitsa), and C.P.; writing-review and editing, A.P. and Y.K. All authors have read and agreed to the published version of the manuscript.

Funding: This research was funded by the project "OPENSCREEN-GR: An Open-Access Research Infrastructure of Target-Based Screening Technologies and Chemical Biology for Human and Animal Health, Agriculture and Environment" (MIS 5002691), which is implemented under the Action "Reinforcement of the Research and Innovation Infrastructure", funded by the Operational Programme "Competitiveness, Entrepreneurship and Innovation" (NSRF 2014-2020) and co-financed by Greece and the European Union (European Regional Development Fund).

Acknowledgments: The authors thank C. Tassou for providing full access to the Microplate Reader, N. Chorianopoulos for his valuable technical support and scientific advice, L. Skaltsounis for providing standard compounds, and G.J.E. Nychas and A. Nisiotou for providing the microbial cultures.

Conflicts of Interest: The authors declare no conflict of interest. The funders had no role in the design of the study, in the collection, analyses, or interpretation of data, in the writing of the manuscript, or in the decision to publish the results.

\section{References}

1. Nakatsu, T.N.; Lupo, A.T.; Chinn, J.W.; Kang, R.K. Biological activity of essential oils and their constituents. Stud. Nat. Prod. Chem. 2000, 21, 571-631. [CrossRef]

2. Rios, J.; Recio, M. Medicinal plants and antimicrobial activity. J. Ethnopharmacol. 2005, 100, 80-84. [CrossRef]

3. Nychas, G.-J.; Skandamis, P.; Tassou, C. Antimicrobials from herbs and spices. In Natural Antimicrobials for the Minimal Processing of Foods; Elsevier BV: Amsterdam, The Netherlands, 2003; pp. 176-200.

4. Burt, S. Essential oils: Their antibacterial properties and potential applications in foods-A review. Int. J. Food Microbiol. 2004, 94, 223-253. [CrossRef] [PubMed]

5. Chorianopoulos, N.G.; Evergetis, E.T.; Aligiannis, N.; Mitakou, S.; Nychas, G.-J.E.; Haroutounian, S.A. Correlation between Chemical Composition of Greek Essential Oils and their Antibacterial Activity against Food-borne Pathogens. Nat. Prod. Commun. 2007, 2, 419-426. [CrossRef]

6. Patelou, E.; Chatzopoulou, P.; Polidoros, A.N.; Mylona, P.V. Genetic diversity and structure of Sideritis raeseri Boiss. \& Heldr. (Lamiaceae) wild populations from Balkan Peninsula. J. Appl. Res. Med. Aromat. Plants 2020, 16, 100241. [CrossRef]

7. Papageorgiou, V.P.; Kokkini, S.; Argyriadou, N. Chemotaxonomy of the Greek Species of Sideritis I. Components of the volatile fraction of Sideritis raeseri ssp. raeseri. In Aromatic Plants; Springer Science and Business Media LLC: Berlin/Heidelberg, Germany, 1982; pp. 211-220.

8. Garzoli, S.; Navarra, A.; Garzoli, S.; Pepi, F.; Ragno, R. Esential oils extraction: A 24-hour steam distillation systematic methodology. Nat. Prod. Res. 2017, 31, 2387-2396. [CrossRef]

9. Aligiannis, N.; Kalpoutzakis, E.; Chinou, I.B.; Mitakou, S.; Gikas, E.; Tsarbopoulos, A. Composition and Antimicrobial Activity of the Essential Oils of Five Taxa of Sideritis from Greece. J. Agric. Food Chem. 2001, 49, 811-815. [CrossRef] [PubMed]

10. Koedam, A. Volatile oil composition of greek mountain tea (Sideritis spp.). J. Sci. Food Agric. 1986, 37, 681-684. [CrossRef]

11. González-Burgos, E.; Carretero, M.; Gómez-Serranillos, M.P. Sideritis spp.: Uses, chemical composition and pharmacological activities-A review. J. Ethnopharmacol. 2011, 135, 209-225. [CrossRef]

12. Stagos, D.; Portesis, N.; Spanou, C.; Mossialos, D.; Aligiannis, N.; Chaita, E.; Panagoulis, C.; Reri, E.; Skaltsounis, L.; Tsatsakis, A.; et al. Correlation of total polyphenolic content with antioxidant and antibacterial activity of 24 extracts from Greek domestic Lamiaceae species. Food Chem. Toxicol. 2012, 50, 4115-4124. [CrossRef]

13. Romanucci, V.; Di Fabio, G.; D’Alonzo, D.; Guaragna, A.; Scapagnini, G.; Zarrelli, A. Traditional uses, chemical composition and biological activities of Sideritis raeseri Boiss. \& Heldr. J. Sci. Food Agric. 2016, 97, 373-383. [CrossRef] 
14. Iqbal, M.N.; Anjum, A.A.; Ali, M.A.; Hussain, F.; Ali, S.; Muhammad, A.; Ahmad, A.; Irfan, M.; Shabbir, A. Assessment of Microbial Load of Un-pasteurized Fruit Juices and in vitro Antibacterial Potential of Honey Against Bacterial Isolates. Open Microbiol. J. 2015, 9, 26-32. [CrossRef]

15. Jay, J.M.; Loessner, M.J.; Golden, D.A. Modern Food Microbiology, 7th ed.; Springer Science Business Media, Inc.: New York, NJ, USA, 2005.

16. Juvonen, R.; Virkajarvi, V.; Priha, O.; Laitila, A. Microbiological Spoilage and Safety Risks in Non-Beer Beverages Produced in a Brewery Environment; VTT Tiedotteita-Research: Espoo, Finland, 2011.

17. Aneja, K.R.; Dhiman, R.; Aggarwal, N.K.; Kumar, V.; Kaur, M. Microbes Associated with Freshly Prepared Juices of Citrus and Carrots. Int. J. Food Sci. 2014, 2014, 1-7. [CrossRef] [PubMed]

18. Mitropoulou, G.; Fitsiou, E.; Spyridopoulou, K.; Tiptiri-Kourpeti, A.; Bardouki, H.; Vamvakias, M.; Panas, P.; Chlichlia, K.; Pappa, A.; Kourkoutas, Y. Citrus medica essential oil exhibits significant antimicrobial and antiproliferative activity. LWT 2017, 84, 344-352. [CrossRef]

19. Chorianopoulos, N.; Lambert, R.; Skandamis, P.; Evergetis, E.; Haroutounian, S.; Nychas, G.-J.E. A newly developed assay to study the minimum inhibitory concentration of Satureja spinosa essential oil. J. Appl. Microbiol. 2006, 100, 778-786. [CrossRef] [PubMed]

20. Lambert, R.; Lambert, R. A model for the efficacy of combined inhibitors. J. Appl. Microbiol. 2003, 95, 734-743. [CrossRef] [PubMed]

21. Arendrup, M.C.; Meletiadis, J.; Mouton, J.W.; Lagrou, K.; Hamal, P.; Guinea, J.; Subcommittee on Antifungal Susceptibility Testing (AFST) of the ESCMID European Committee for Antimicrobial Susceptibility Testing. EUCAST Definitive Document EDEF 9.3.2 Method for the Determination of Broth Dilution Minimum Inhibitory Concentrations of Antifungal Agents for Conidia Forming Moulds. 2020. Available online: https://www.eucast.org/fileadmin/src/media/PDFs/EUCAST_files/AFST/Files/EUCAST_E_Def_9.3. 2_Mould_testing_definitive_revised_2020 (accessed on 7 April 2020).

22. Arendrup, M.C.; Meletiadis, J.; Mouton, J.W.; Lagrou, K.; Hamal, P.; Guinea, J.; Subcommittee on Antifungal Susceptibility Testing (AFST) of the ESCMID European Committee for Antimicrobial Susceptibility Testing. EUCAST Definitive Document EDEF 7.3.2 Method for the Determination of Broth Dilution Minimum Inhibitory Concentrations of Antifungal Agents for Yeasts. 2020. Available online: https://www.eucast.org/fileadmin/src/media/PDFs/EUCAST_files/AFST/Files/EUCAST_E_Def_7.3. 2_Yeast_testing_definitive_revised_2020 (accessed on 8 April 2020).

23. Balkan, C.; Ercan, I.; Isik, E.; Akdeniz, E.S.; Balcioglu, O.; Kodedová, M.; Zimmermannová, O.; Dundar, M.; Sychrová, H.; Koc, A. Genomewide Elucidation of Drug Resistance Mechanisms for Systemically Used Antifungal Drugs Amphotericin B, Caspofungin, and Voriconazole in the Budding Yeast. Antimicrob. Agents Chemother. 2019, 63. [CrossRef]

24. Mandras, N.; Roana, J.; Scalas, D.; Fucale, G.; Allizond, V.; Banche, G.; Barbui, A.; Vigni, N.L.; Newell, V.A.; Cuffini, A.M.; et al. In vitro antifungal activity of fluconazole and voriconazole against non-Candida yeasts and yeast-like fungi clinical isolates. New Microbiol. 2015, 38, 583-587.

25. Lee, S.K.; Mbwambo, Z.H.; Chung, H.; Luyengi, L.; Gamez, E.J.; Mehta, R.G.; Kinghorn, A.D.; Pezzuto, J.M. Evaluation of the antioxidant potential of natural products. Comb. Chem. High Throughput Screen. 1998, 1, 35.

26. Re, R.; Pellegrini, N.; Proteggente, A.; Pannala, A.; Yang, M.; Rice-Evans, C. Antioxidant activity applying an improved ABTS radical cation decolorization assay. Free. Radic. Boil. Med. 1999, 26, 1231-1237. [CrossRef]

27. Fitsiou, E.; Mitropoulou, G.; Spyridopoulou, K.; Tiptiri-Kourpeti, A.; Vamvakias, M.; Bardouki, H.; Panayiotidis, M.; Galanis, A.; Kourkoutas, Y.; Chlichlia, K.; et al. Phytochemical Profile and Evaluation of the Biological Activities of Essential Oils Derived from the Greek Aromatic Plant Species Ocimum basilicum, Mentha spicata, Pimpinella anisum and Fortunella margarita. Molecules 2016, 21, 1069. [CrossRef]

28. Olive, P.L.; Banáth, J.P. The comet assay: A method to measure DNA damage in individual cells. Nat. Protoc. 2006, 1, 23-29. [CrossRef]

29. Fitsiou, E.; Mitropoulou, G.; Spyridopoulou, K.; Vamvakias, M.; Bardouki, H.; Galanis, A.; Chlichlia, K.; Kourkoutas, Y.; Panayiotidis, M.; Pappa, A. Chemical Composition and Evaluation of the Biological Properties of the Essential Oil of the Dietary Phytochemical Lippia citriodora. Molecules 2018, 23, 123. [CrossRef] [PubMed]

30. Panagiotidis, M.; Tsolas, O.; Galaris, D. Glucose oxidase-produced $\mathrm{H}_{2} \mathrm{O}_{2}$ induces $\mathrm{Ca}^{2+}$-dependent DNA damage in human peripheral blood lymphocytes. Free Radic. Boil. Med. 1999, 26, 548-556. [CrossRef]

31. Kirmızıbekmez, H.; Karaca, N.; Demirci, F. Characterization of Sideritis trojana Bornm. essential oil and its antimicrobial activity. Marmara Pharm. J. 2017, 21, 860-865. [CrossRef] 
32. Kirimer, N.; Baser, K.H.C.; Demirci, B.; Duman, H. Essential Oils of Sideritis Species of Turkey Belonging to the Section Empedoclia. Chem. Nat. Compd. 2004, 40, 19-23. [CrossRef]

33. Chorianopoulos, N.; Kalpoutzakis, E.; Aligiannis, N.; Mitaku, S.; Nychas, G.-J.E.; Haroutounian, S.A. Essential Oils of Satureja, Origanum, and Thymus Species: Chemical Composition and Antibacterial Activities Against Foodborne Pathogens. J. Agric. Food Chem. 2004, 52, 8261-8267. [CrossRef]

34. Battey, A.S.; Duffy, S.; Schaffner, D. Modeling Yeast Spoilage in Cold-Filled Ready-To-Drink Beverages with Saccharomyces cerevisiae, Zygosaccharomyces bailii, and Candida lipolytica. Appl. Environ. Microbiol. 2002, 68, 1901-1906. [CrossRef]

35. Garcia, D.; Ramos, A.J.; Sanchis, V.; Marín, S. Predicting mycotoxins in foods: A review. Food Microbiol. 2009, 26, 757-769. [CrossRef]

36. Deveci, E.; Tel-Çayan, G.; Usluer, Ö.; Duru, M.E. Chemical Composition, Antioxidant, Anticholinesterase and Anti-Tyrosinase Activities of Essential Oils of Two Sideritis Species from Turkey. Iran J. Pharm. Res. 2019, 18, 903-913.

37. Deveci, E.; Tel-Çayan, G.; Duru, M.E.; Öztürk, M. Phytochemical contents, antioxidant effects, and inhibitory activities of key enzymes associated with Alzheimer's disease, ulcer, and skin disorders of Sideritis albiflora and Sideritis leptoclada. J. Food Biochem. 2019, 43, e13078. [CrossRef]

38. Gabrieli, C.; Kefalas, P.; Kokkalou, E. Antioxidant activity of flavonoids from Sideritis raeseri. J. Ethnopharmacol. 2005, 96, 423-428. [CrossRef] [PubMed]

39. Da Silva, L.C.N.; Filho, C.M.B.; De Paula, R.A.; Silva, C.S.S.E.; De Souza, L.I.O.; Da Silva, L.C.N.; Correia, M.T.D.S.; De Figueiredo, R.C.B.Q. In vitro cell-based assays for evaluation of antioxidant potential of plant-derived products. Free. Radic. Res. 2016, 50, 801-812. [CrossRef] [PubMed]

40. González-Burgos, E.; Duarte, A.I.; Carretero, M.E.; Moreira, P.; Gómez-Serranillos, M.P. MitochondrialTargeted Protective Properties of Isolated Diterpenoids from Sideritis spp. in Response to the Deleterious Changes Induced by $\mathrm{H}_{2} \mathrm{O}_{2}$. J. Nat. Prod. 2013, 76, 933-938. [CrossRef] [PubMed]

41. Tóth, B.; Kúsz, N.; Forgo, P.; Bózsity, N.; Zupkó, I.; Pinke, G.; Hohmann, J.; Vasas, A. Abietane diterpenoids from Sideritis montana L. and their antiproliferative activity. Fitoterapia 2017, 122, 90-94. [CrossRef]

42. Tadić, V.; Jeremic, I.; Dobrić, S.; Isakovic, A.; Marković, I.; Trajkovic, V.; Bojović, D.; Arsić, I. Anti-inflammatory, Gastroprotective, and Cytotoxic Effects of Sideritis scardica Extracts. Planta Med. 2012, 78, 415-427. [CrossRef]

43. Jorge, L.; Meniqueti, A.; Silva, R.; Santos, K.; Da Silva, E.A.; Gonçalves, J.E.; De Rezende, C.; Colauto, N.B.; Gazim, Z.; Linde, G. Antioxidant activity and chemical composition of oleoresin from leaves and flowers of Brunfelsia uniflora. Genet. Mol. Res. 2017, 16. [CrossRef]

44. Tian, M.; Liu, T.; Wu, X.; Hong, Y.; Liu, X.; Lin, B.; Zhou, Y. Chemical composition, antioxidant, antimicrobial and anticancer activities of the essential oil from the rhizomes of Zingiber striolatum Diels. Nat. Prod. Res. 2019, 25, 1-5. [CrossRef] [PubMed]

45. Demiray, H.; Tabanca, N.; Estep, A.S.; Becnel, J.J.; Demirci, B. Chemical composition of the essential oil and $n$-hexane extract of Stachys tmolea subsp. Tmolea Boiss., an endemic species of Turkey, and their mosquitocidal activity against dengue vector Aesdes aegypti. Saudi Pharm. J. 2019, 27, 877-881. [CrossRef] [PubMed]

(C) 2020 by the authors. Licensee MDPI, Basel, Switzerland. This article is an open access article distributed under the terms and conditions of the Creative Commons Attribution (CC BY) license (http://creativecommons.org/licenses/by/4.0/). 